\title{
Thermogravimetric and Kinetic Analysis of Melon (Citrullus colocynthis L.) Seed Husk Using the Distributed Activation Energy Model
}

\author{
Bemgba Bevan NYAKUMA*, \\ Universiti Teknologi Malaysia, 1310 UTM Skudai, Johor Bahru, Malaysia
}

\begin{abstract}
This study seeks to characterize the thermochemical fuel properties of melon seed husk (MSH) as a potential biomass feedstock for clean energy and power generation. It examined the ultimate analysis, proximate analysis, FTIR spectroscopy and thermal decomposition of MSH. Thermogravimetric (TG) analysis was examined at $5,10,20{ }^{\circ} \mathrm{C} / \mathrm{min}$ from $30-800{ }^{\circ} \mathrm{C}$ under nitrogen atmosphere. Subsequently, the Distributed Activation Energy Model (DAEM) was applied to determine the activation energy, $E$, and frequency factor, $A$. The results revealed that thermal decomposition of MSH occurs in three (3) stages; drying $\left(30-150{ }^{\circ} \mathrm{C}\right)$, devolatization $\left(150-400{ }^{\circ} \mathrm{C}\right)$ and char degradation $\left(400-800{ }^{\circ} \mathrm{C}\right)$. Kinetic analysis revealed that the $E$ values fluctuated from $145.44-300 \mathrm{~kJ} / \mathrm{mol}$ (Average $E=$ $193 \mathrm{~kJ} / \mathrm{mol}$ ) while $A$ ranged from $2.64 \times 10^{10}$ to $9.18 \times 10^{20} \mathrm{~min}^{-1}$ (Average $E=9.18 \times 10^{19}$ $\min ^{-1}$ ) highlighting the complexity of MSH pyrolysis. The fuel characterization and kinetics of MSH showed it is an environmentally friendly solid biofuel for future thermal biomass conversion.
\end{abstract}

Keywords - Activation energy; husks; kinetics; melon; thermogravimetric

\begin{tabular}{|lll}
\hline \multicolumn{2}{l}{ Nomenclature } & \\
Symbol & & Unit \\
$\Phi(E, T)$ & Temperature dependent activation energy & $\mathrm{kJ} / \mathrm{mol}$ \\
$\alpha$ & Degree of conversion & - \\
$A$ & Frequency Factor & $\mathrm{min}^{-1}$ \\
$A_{i}$ & Frequency Factor for $i$ th order & $\mathrm{min}^{-1}$ \\
$A C$ & Ash content & $\mathrm{wt} . \%$ \\
$\beta$ & Heating rate & ${ }^{\circ} \mathrm{C} / \mathrm{min}$ \\
$C H N S O$ & Carbon, Hydrogen, Nitrogen, Sulphur, Oxygen & $\mathrm{wt} . \%$ \\
$d E$ & Change in Activation Energy & $\mathrm{kJ} / \mathrm{mol}$ \\
$D A E M$ & Distributed Activation Energy Model & - \\
$E$ & Activation Energy & $\mathrm{kJ} / \mathrm{mol}$ \\
$E s$ & Step function for Activation Energy & - \\
$f(E)$ & Normalised Activation Energy & $\mathrm{kJ} / \mathrm{mol}$ \\
$F C$ & Fixed Carbon & $\mathrm{wt} . \%$ \\
$F T I R$ & Fourier Transform Infra-Red & - \\
$i t h$ & Reaction order & - \\
\hline
\end{tabular}

\footnotetext{
* Corresponding author.

E-mail address: bnbevan2@live.utm.my
} 


\begin{tabular}{|lll|}
\hline$M$ & Moisture content & wt. \% \\
$M S H$ & Melon Seed Husk & \\
$M_{L R}$ & Mass Loss Rate & $\%$ \\
$M_{R}$ & Residual Mass & $\mathrm{J} / \mathrm{mol} / \mathrm{K}$ \\
$R$ & Universal Gas Constant & - \\
$R^{2}$ & Correlation coefficient & $\mathrm{s}$ \\
$t$ & Time & - \\
$S B F$ & Solid Biomass Fuels & $\mathrm{K}$ \\
$T$ & Absolute Temperature & - \\
$T G$ & Thermogravimetric Analysis & $\left({ }^{\circ} \mathrm{C}\right)$ \\
$T_{p}$ & Peak Decomposition Temperature & - \\
$D T G$ & Derivative Thermogravimetric Analysis & - \\
$V$ & Total volatiles content & - \\
$V_{\infty}$ & Effective fuel volatile content & - \\
$V_{i}$ & Initial mass of Volatiles & - \\
$V_{i \infty}$ & Effective Volatiles for $i$ ith order of reaction & wt. \% \\
$V M$ & Volatile Matter & \\
\hline
\end{tabular}

\section{INTRODUCTION}

Global interest in biomass as a renewable source of clean biofuels, green chemicals and power generation is gaining momentum. Biomass is a clean, abundant and renewable source of nonpolluting biofuels for future applications [1], [2]. Furthermore, the wide variety of biomass resources and its wide geographical distribution aptly positions it as the most practical renewable energy technology (RET) for implementing future energy transitions from fossil fuels. This is particularly important in developing countries where the cultivation of various agricultural crops and perennial grasses generates large quantities of lignocellulosic biomass resources annually.

The cultivation of Melon (Citrullus colocynthis L.) an important oil-rich crop also known as Egusi in Nigeria has increased significantly to over 500,000 tonnes per annum [3]. This is primarily due to the growing importance of melon seed oil as feedstock for biodiesel production [4], [5], food and cosmetics [6], [7], medicinal purposes [8], [9]. However the cultivation and extraction of vegetable oil from melon seeds generates large quantities of lignocellulosic waste known as MSH [10]. Current waste management strategies for disposing MSH include open air burning, incineration and deposition in landfill sites and refuse dumps. These disposal methods are obsolete, inefficient and potentially detrimental to human health, safety and the environment through increased air and water pollution, land degradation and disruption of water bodies.

Hence, it is imperative for researchers to explore novel technologies for valorizing and utilizing MSH. Consequently, MSH is currently utilized as weed suppressants, organic fertilizers, mulching material [11], water treatment and purification [10], [12] with varying degrees of success, which leaves scope for further studies on MSH valorization. Therefore, an alternative, albeit potentially more efficient waste disposal strategy involves the utilization of MSH as a feedstock for clean energy fuels and power generation. This can be achieved by 
employing practical to energy technologies such as torrefaction, pyrolysis and gasification [13] [16].

The application of the outlined low carbon technologies (LCT) can potentially mitigate the uncontrolled emission of GHGs from burning, landfilling and reduce the associated costs of managing solid wastes [17], [18] such as MSH in the future. To the best of the author's knowledge there is no published information in literature on the thermochemical characterization and potential utilization of MSH as a solid biofuel (SBF) for clean energy and power generation. Hence, the comprehensive characterization of the thermochemical fuel properties of MSH is essential to ascertain its potential for application in biomass conversion processes.

The most commonly applied technique for characterizing the fuel thermochemical properties of potential solid biomass fuels (SBF) is thermogravimetric (TG) analysis [19]-[21]. This technique has been extensively utilized to investigate the thermal behaviour and decomposition kinetics of potential biomass resources [22], [23]. By applying TGA data, biomass decomposition can be investigated using various kinetic models including the distributed activation energy model (DAEM) [24], [25].

The DAEM model is considered the most accurate and reliable pseudo-mechanistic approach for characterising and modelling the decomposition kinetics of biomass under pyrolysis conditions [26]. This ultimately provides scientists, engineers and decision makers with critical information required for the planning, design, modelling of operating processes required for implementing biomass energy conversion systems for clean energy and power generation.

Therefore, this study seeks to characterise the solid biofuel (SBF) properties of MSH and examine its thermal decomposition kinetics using the DAEM model. It presents vital information on the heating value, proximate and ultimate analysis as well as thermal degradation behaviour of MSH during thermogravimetric analysis under inert conditions. Additionally, the kinetic parameters; activation energy, $E$, and Frequency factor, $A$, of $\mathrm{MSH}$ decomposition using the distributed activation energy model (DAEM) is also presented in detail. The data presented will potentially serve as vital reference material for future biomass energy conversion systems utilizing MSH as feedstock.

\section{EXPERIMENTAL}

\subsection{Materials and Methods}

Melon seeds were purchased from a local market in Nigeria and de-hulled to obtain the MSH investigated in this study. The MSH was pulverised in a dry miller and sieved with an analytical sieve to obtain particles below $250 \mu \mathrm{m}$. MSH was subsequently characterised by ultimate analysis using the Vario Micro Cube CHNS/O analyser. Proximate analysis was determined using standard ASTM techniques: E871 for moisture, E872-82 for volatile matter and D1102-84 for ash content while fixed carbon content was determined by difference. The ultimate and proximate analysis of MSH is reported in dry ash free (daf) and dry basis $(d b)$ respectively in Table 1. The heating value was calculated from the ultimate analysis of MSH using the Channiwala and Parikh formula [27].

The thermal decomposition behaviour of MSH was investigated using the Netzsch 209 F3 Thermogravimetric (TG) analyser. About $8 \mathrm{mg}$ of powdered MSH sample was heated in an alumina crucible from $30{ }^{\circ} \mathrm{C}$ to $800{ }^{\circ} \mathrm{C}$ using three heating rates 5,10 and $20{ }^{\circ} \mathrm{C} / \mathrm{min}$. The system was purged with ultra-pure $(99.99 \%$ ) nitrogen gas at a flowrate of $50 \mathrm{ml} / \mathrm{min}$ during thermal analysis. The weight loss of MSH as function of temperature was recorded and the resulting TG data was subsequently analysed using the Proteus 6.1 software. 
Next, the distributed activation energy model (DAEM) was applied to the MSH TG data to determine the kinetic parameters; Activation Energy $(E)$ and Frequency Factor $(A)$ according to Eq. 1-10.

\subsection{Distributed Action Energy Model (DAEM)}

The decomposition kinetics of MSH was examined using the DAEM model proposed in 1943 by Vladimir Vand [20]. The model is based on the assumption that thermal degradation of solid biomass fuels (SBF) is governed by a set of first order irreversible reactions occurring concurrently [28]. The DAEM model has been successfully applied to characterize the change in the overall conversion and yield of a reacting components during thermal degradation [20], [29].

According to DAEM, the change in volatiles during the pyrolysis of MSH can be expressed by:

$$
1-\frac{V}{V_{\infty}}=\int_{0}^{\infty} \Phi(E, T) f(E) d E
$$

where

$V \quad$ total volatiles changed at time $t$;

$V_{\infty} \quad$ effective fuel volatile content;

$\Phi(E, T)$ temperature dependent activation energy $E$;

$f(E)$ normalised activation energy distribution curve for the irreversible first order reactions

A frequency factor.

The function $\Phi(E, T)$ for MSH devolatization at a definite heating rate, $\beta$, can be expressed mathematically by the relation [28], [30]:

$$
\Phi(E, T)=\exp \left(-\frac{A}{\beta} \int_{T_{0}}^{T} e^{-E / R T} d T\right)
$$

By presenting a step function at $E=E_{s}$ for a selected temperature, $T$, at a constant heating rate, $\beta$, and the Muira [28] numerical estimation, the function $\Phi(E, T)$ can be simplified:

$$
1-\frac{V}{V_{\infty}}=\int_{E s}^{\infty} f(E) d E
$$

This is valid only for $E$ at $\Phi(E, T)=0.58$ for different combinations of $A$ and $E$, hence the expression for $A$ corresponding to $E$, at the heating rate $\beta$ can be rewritten as:

$$
0.545 \frac{\beta E}{A R T^{2}}=e^{-E / R T}
$$

The approximate equation for $\Phi(E, T)$ expressed as:

$$
\Phi(E, T) \cong \exp \left(-\frac{A R T^{2}}{\beta E} e^{-\frac{E}{R T}}\right)
$$

This approximation can be used to treat $i$ th reactions occurring at temperature $T$, and constant heating rate, $\beta$ as presented in Eq. 6 [30]:

$$
\frac{d\left(V / V_{\infty}\right)}{d T} \cong \frac{d\left(V_{i} / V_{\infty}\right)}{d T}=\frac{A_{i}}{\beta} \exp \left(-\frac{E_{i}}{R T}\right)\left(\frac{V_{i \infty}}{V_{\infty}}-\frac{V_{i}}{V_{\infty}}\right)
$$

Consequently, the complete rate of reaction can be derived from the approximation by taking into account $V_{i}$, the amount of volatiles evolved and $V_{i \infty}$ the effective volatiles for $i$ th single first order reactions at temperature $T$. 
Hence, an expression for the rate of devolatization at constant heating rates can be deduced by integrating Eq. 6 to yield the expression:

$$
1-\frac{V_{i}}{V_{i \infty}}=\cong \exp \left(-\frac{A_{i} R T^{2}}{\beta E} e^{-\frac{E_{i}}{R T}}\right)
$$

By taking natural logarithm and separation of variables Eq. 7 can be rewritten as:

$$
\ln \left(\frac{\beta}{T^{2}}\right)=\ln \left(\frac{A R}{E}\right)-\ln \left[-\ln \left(1-\frac{V_{i}}{V_{i \infty}}\right)\right]-\left(\frac{E}{R T}\right)
$$

A simplified form of Eq. 8 can be obtained for a linear relationship between the kinetic parameters, $\beta, A, E$ and $T$; by considering Eq. 9:

$$
1-\frac{V}{V_{\infty}}=\Phi(E, T)=0.58
$$

Consequently, the mathematical expression for the DAEM model which describes the relationship between the kinetic parameters $E$, and $A$, during thermal decomposition can be expressed as:

$$
\ln \left(\frac{\beta}{T^{2}}\right)=\ln \left(\frac{A R}{E}\right)+0.6075-\frac{E}{R} \frac{1}{T}
$$

Therefore, by plotting in $\left(\beta / \mathrm{T}^{2}\right)$ vs $(1 / \mathrm{T})$, the activation energy, $E$, and frequency factor, $A$, can be deduced from slope of the linear fitting curve and the intercept, respectively.

\section{ReSUlts AND DiscuSSION}

\subsection{Fuel Properties}

Table 1 presents the thermochemical fuel properties of MSH in terms of its elemental composition, proximate analysis and higher heating value in $\mathrm{MJ} / \mathrm{kg}$. The values are presented in wt. \% daf and wt. \% $d b$ basis for comparison with values for other biomass in literature [31].

TABLE 1. CHEMICAL Fuel PROPERTIES OF MSH

\begin{tabular}{lll}
\hline Element & Symbol & Proportion (wt. \%) \\
\hline Carbon & $\mathrm{C}$ & 52.16 \\
Hydrogen & $\mathrm{H}$ & 6.71 \\
Nitrogen & $\mathrm{N}$ & 0.82 \\
Sulphur & $\mathrm{S}$ & 0.15 \\
Oxygen & $\mathrm{O}$ & 40.16 \\
Moisture & $\mathrm{M}$ & 6.97 \\
Volatiles & $\mathrm{VM}$ & 77.32 \\
Ash & $\mathrm{AC}$ & 2.02 \\
Fixed Carbon & FC & 20.66 \\
Higher Heating Value & HHV & 21.93 \\
\hline
\end{tabular}

The results indicate that $\mathrm{MSH}$ has high $\mathrm{C}, \mathrm{H}, \mathrm{O}, \mathrm{VM}$ and $\mathrm{FC}$ content while the $\mathrm{N}, \mathrm{S}, \mathrm{M}$, and $\mathrm{A}$ are lower that the values reported for other solid biomass fuels (SBF) in literature [31]. The MSH heating value (HHV) of $21.93 \mathrm{MJ} / \mathrm{kg}$ is higher than other agricultural waste residues such as groundnut shells (16.91 MJ/kg) [32]; walnut shell (17.86 MJ/kg) [33]; corn cobs 
(16.63 MJ/kg), oil palm empty fruit bunches $(17.57 \mathrm{MJ} / \mathrm{kg})[34,35]$ and cassava stalk $(17.58$ $\mathrm{MJ} / \mathrm{kg}$ ) [36] in literature. This is primarily due to the high C, VM, and FC which accounts for the combustible content of MSH.

The low $\mathrm{N}$ and $\mathrm{S}$ content indicates the thermal conversation of $\mathrm{MSH}$ will potentially result in low emissions of nitrous, sulfur oxides and other GHGs into the atmosphere during thermal conversion. This effectively highlights the environmentally friendly potential of the MSH as a potential SBF for future thermochemical applications. Furthermore, the low ash (A) and moisture (M) content of MSH also presents important advantages in considering $\mathrm{MSH}$ as a viable SBF. With low ash properties, MSH is unlikely to present slagging and agglomeration problems during thermal conversion while low moisture will enhance the efficiency of thermal conversion.

\subsection{Fourier Transform Infra-Red Spectroscopy}

The FTIR study was carried out to ascertain the functional groups present in the chemical structure of $\mathrm{MSH}$ which can be used to predict the potential products of thermochemical conversion. The FTIR spectrum of MSH from $4000-400 \mathrm{~cm}^{-1}$ is presented in Figure 1.

The bands observed from $3700-3900 \mathrm{~cm}^{-1}$ are typically assigned to the rota-vibrational band of water vapour as reported in the moisture content of MSH in Table 1. In addition, the strong broad band from 3000-3700 $\mathrm{cm}^{-1}$ denotes the presence of free and intermolecular -OH groups predominantly observed in alcohols, phenols, lignin and other carbohydrates [37], [38]. Conversely, this could also be due to the symmetric or asymmetric stretching vibrations of water molecules in the MSH structure.

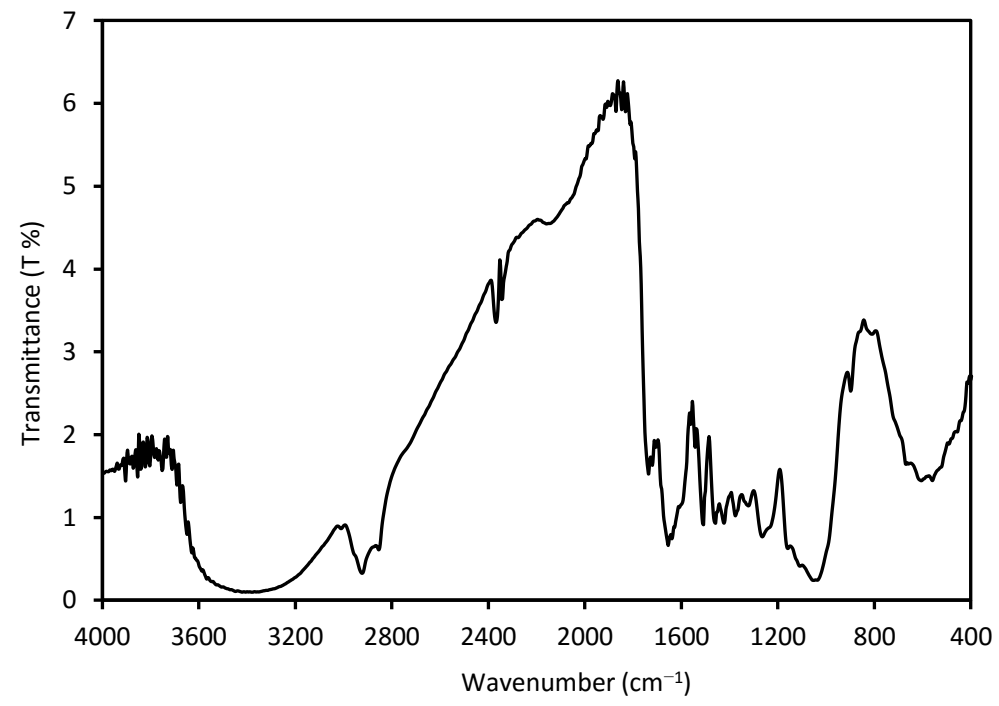

Fig. 1. FTIR spectrum of MSH.

The peaks $2924 \mathrm{~cm}^{-1}, 2862 \mathrm{~cm}^{-1}, 1423 \mathrm{~cm}^{-1}$ and $1458 \mathrm{~cm}^{-1}$ are due to the symmetric and asymmetric $\mathrm{C}-\mathrm{H}$ stretching vibrations often associated with aliphatic $-\mathrm{CH}_{3}$ - and $-\mathrm{CH}_{2}-$ groups which typically constitute the major chemical structure of lignocellulosic biomaterials [39]. The small peaks observed at $2372 \mathrm{~cm}^{-1}$ and $2156 \mathrm{~cm}^{-1}$ can be assigned to $-\mathrm{C} \equiv \mathrm{C}$ - or $-\mathrm{C} \equiv \mathrm{N}$ - stretching vibrations typical of alkynes or nitriles which occur in a wide variety of natural products and heterocyclic compounds isolated from plants. The medium peak observed at $1654 \mathrm{~cm}^{-1}$ can be 
assigned to the $-\mathrm{C}=\mathrm{C}$ - stretching vibrations in alkenes while the sharp peak at $1512 \mathrm{~cm}^{-1}$ is due to the in-ring -C-C-stretch vibrations typical of unsaturated aromatic compounds [37]. At 1735 $\mathrm{cm}^{-1}$ and $1327 \mathrm{~cm}^{-1}$ the weak peaks in the spectrum can be ascribed to the $-\mathrm{C}=\mathrm{O}$ - stretching vibrations typically observed in carbonyls particularly alcohols, carboxylic acids, esters and aldehydes. The broad peak at $1261 \mathrm{~cm}^{-1}$ can be ascribed to the $-\mathrm{C}-\mathrm{N}$ - stretching vibrations found in aliphatic amines.

The broad band at $1045 \mathrm{~cm}^{-1}$ can be attributed to $\mathrm{C}-\mathrm{O}-\mathrm{H}$ or $\mathrm{C}-\mathrm{O}-\mathrm{R}$ alcohols or ester groups [21], [37] while the sharp peak at $902 \mathrm{~cm}^{-1}$ can be attributed to $-\mathrm{C}-\mathrm{H}$ - groups in aromatics. Overall, the FTIR spectrum indicates the chemical structure of MSH is possibly due to contributions from alcohol, aldehyde, aliphatic, aromatic, ester and ketonic groups normally associated with hemicellulose, cellulose and lignin in biomass materials.

\subsection{Thermogravimetric Analysis (TGA)}

The weight loss curves for the thermal decomposition of MSH at different heating rates 5, 10, and $20{ }^{\circ} \mathrm{C} / \mathrm{min}$ denoted MSH-5, MSH-10 and MSH-20 from $30-800{ }^{\circ} \mathrm{C}$ are presented in Fig. 2. The curves display the distinctive Z-shaped downward sloping curves typically observed in thermally decomposing biomass materials.

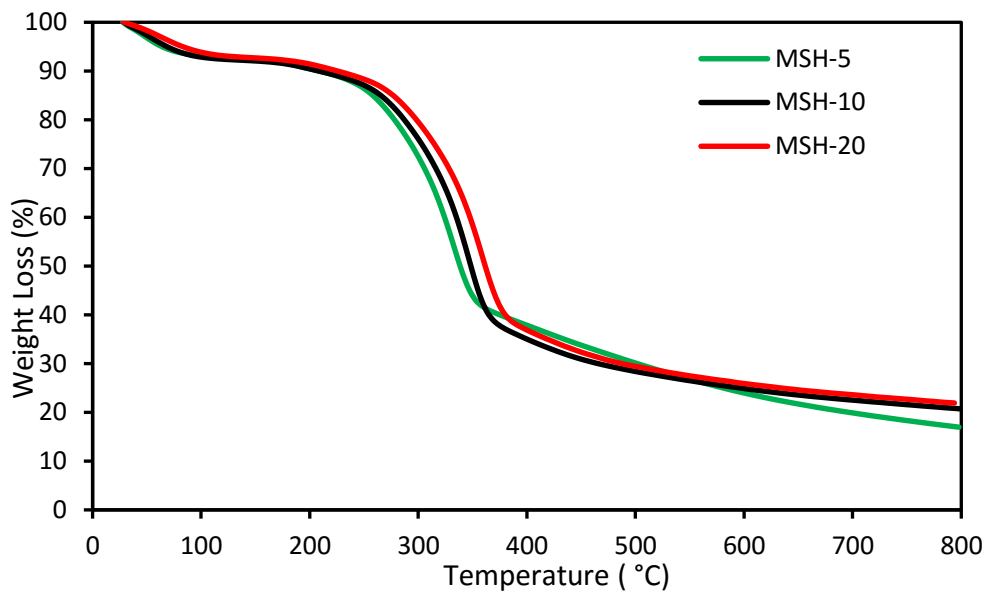

Fig. 2. Weight Loss (\%) TG Curves for $\mathrm{MSH}$ at 5, 10 and $20^{\circ} \mathrm{C} \mathrm{min}^{-1}$.

From Fig. 2 it can be observed that the effect of increased heating rate was significant during thermal analysis as indicated in the TG curves. Consequently, the increase in heating rates caused a shift in the TG curves to higher temperatures resulting in changes in the temperature profile characteristics of MSH (Table 2), as also observed by other researchers in literature [40][42]. This has been attributed to heat transfer limitations due to the different thermal efficiencies available at higher heating rates. In principle, thermal decomposition of biomass at low heating rates ensures more efficient heat transfer and thermal energy into the particles, which results in a longer equilibrating time for the purge gas and furnace to reach the same temperature [43], [44].

Conversely, at higher heating rates a shorter reaction and higher temperature is required for biomass degradation during thermal analysis which causes the TG curves to shift to higher temperatures [42], [45]. Table 2 presents an overview of the effect of increased heating rate on the temperature profile characteristics of MSH during thermal decomposition. 
TABLE 2. EFFECT OF HEATING RATE ON MSH DECOMPOSITION

\begin{tabular}{cccc}
\hline $\begin{array}{c}\text { Heating Rate, } \boldsymbol{\beta} \\
\left({ }^{\circ} \mathbf{C} / \mathbf{m i n}\right)\end{array}$ & $\begin{array}{c}\text { Peak Decomposition } \\
\text { Temp, }\left(\boldsymbol{T}_{\boldsymbol{p}}\right)\end{array}$ & $\begin{array}{c}\text { Mass Loss Rate, } \mathbf{M}_{\boldsymbol{L} R} \\
(\boldsymbol{\%} / \mathbf{m i n}) \text { at } \boldsymbol{T}_{\boldsymbol{p}}\end{array}$ & $\begin{array}{c}\text { Residual mass, } \boldsymbol{M}_{\boldsymbol{R}} \\
(\boldsymbol{\%})\end{array}$ \\
\hline 5 & 332.60 & 3.57 & 16.97 \\
10 & 346.50 & 7.85 & 20.68 \\
20 & 358.20 & 14.53 & 21.87 \\
\hline
\end{tabular}

The results clearly indicate that increasing the heating rate significantly influences the temperature profile characteristics of MSH during thermal decomposition. Most notably, the maximum decomposition peak temperature, $T_{p}$, of $\mathrm{MSH}$ increased by an average of $12.8{ }^{\circ} \mathrm{C}$ from $332.60{ }^{\circ} \mathrm{C}$ to $358.20{ }^{\circ} \mathrm{C}$ as the heating rate was increased from $5{ }^{\circ} \mathrm{C} / \mathrm{min}$ to $20{ }^{\circ} \mathrm{C} / \mathrm{min}$ during thermal analysis. This indicates that increasing the heating rate by a factor of 2 resulted in an increase in the $T_{p}$ by over $10^{\circ} \mathrm{C}$ during thermal degradation of $\mathrm{MSH}$. Furthermore, the effect of heating of rate was also evident in the mass loss rate, $M_{L R}$, of the fuel which primarily occurs at $T_{p}$. Likewise the values for $M_{L R}$ increased significantly due to the effect of increase in heating rate. The residual mass, $M_{R}$ values, a measure of the extent of biochar formation, increased from $16.97 \%$ to $21.87 \%$ with increasing heating rate from $5{ }^{\circ} \mathrm{C} / \mathrm{min}$ to $20{ }^{\circ} \mathrm{C} / \mathrm{min}$. Hence, the pyrolytic thermal decomposition of $\mathrm{MSH}$, under the reaction conditions, resulted in over $78 \%$ degradation of the sample. Overall, the results can be used to somewhat predict the possible products of the thermal decomposition of $\mathrm{MSH}$ under the reaction conditions (RT to $800{ }^{\circ} \mathrm{C}$ ) yielding more liquids/gases over solids (biochar).

\subsection{Derivative Thermal Gravimetric analysis (DTG)}

The DTG curves for the thermal decomposition of MSH are presented in Figure 3. The DTG curves provide a more detailed representation of the mechanism of thermal decomposition of the sample [37]. In all cases, it was observed that increase in heating rates also caused an enlargement in size of the DTG curves and temperature profiles of MSH without a change in the thermal profile.

This may be due to an increase in the rate of devolatization and weight loss of the fuel at higher heating rates observed in mass loss rates $\left(M_{L R}\right)$. In addition, the thermal decomposition behaviour of MSH suggests that the reaction mechanism is independent of heating rate as similarly observed for other biomass in literature [37]. 


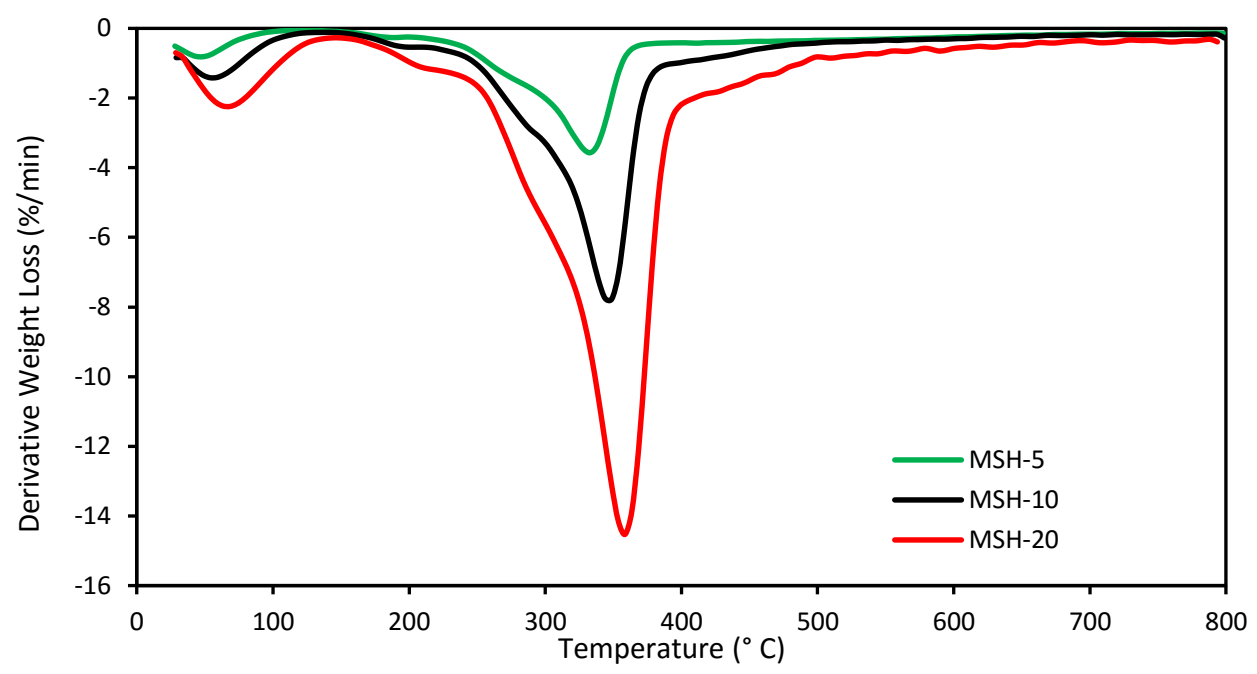

Fig. 3. DTG Curves for $\mathrm{MSH}$ at 5,10 and $20^{\circ} \mathrm{C} \mathrm{min}^{-1}$.

Furthermore, the results indicate the thermal decomposition of MSH occurs in three stages namely; drying $\left(30-150{ }^{\circ} \mathrm{C}\right)$, devolatization $\left(150-400{ }^{\circ} \mathrm{C}\right)$ and char degradation $\left(400-800{ }^{\circ} \mathrm{C}\right)$, as corroborated by other research groups in literature [37], [41], [42]. The drying stage of pyrolysis of biomass samples ensures the removal of surface moisture and partial removal of volatiles at temperatures below $150{ }^{\circ} \mathrm{C}$. The second stage involves exothermic reactions which ensure the removal of volatiles (devolatization) and lignocellulosic the biomass components; hemicellulose, cellulose and lignin.

Due to the large extent of weight loss occurring during this stage of pyrolysis, it is also known as the region of active pyrolysis. The final stage involves the endothermic decomposition of lignin at temperatures above $400{ }^{\circ} \mathrm{C}$ [21] denoted by the long tailing in the DTG curve of MSH.

\subsection{Kinetic Analysis}

The kinetic parameters activation energy, $E$, and frequency factor, $A$, for MSH decomposition were deduced using DAEM model as described in literature [30]. Furthermore, the DAEM model reflects the $E$ distribution of pyrolytic mass conversions at different heating rates. Figure 4 presents the plots for the kinetic parameters $E$ and $A$ for MSH conversion from $\alpha=0.15-0.60$. However MSH conversions below 0.15 and above 0.6 have been excluded due to low correlation values, as similarly reported by other groups [21], [37], [41]. 


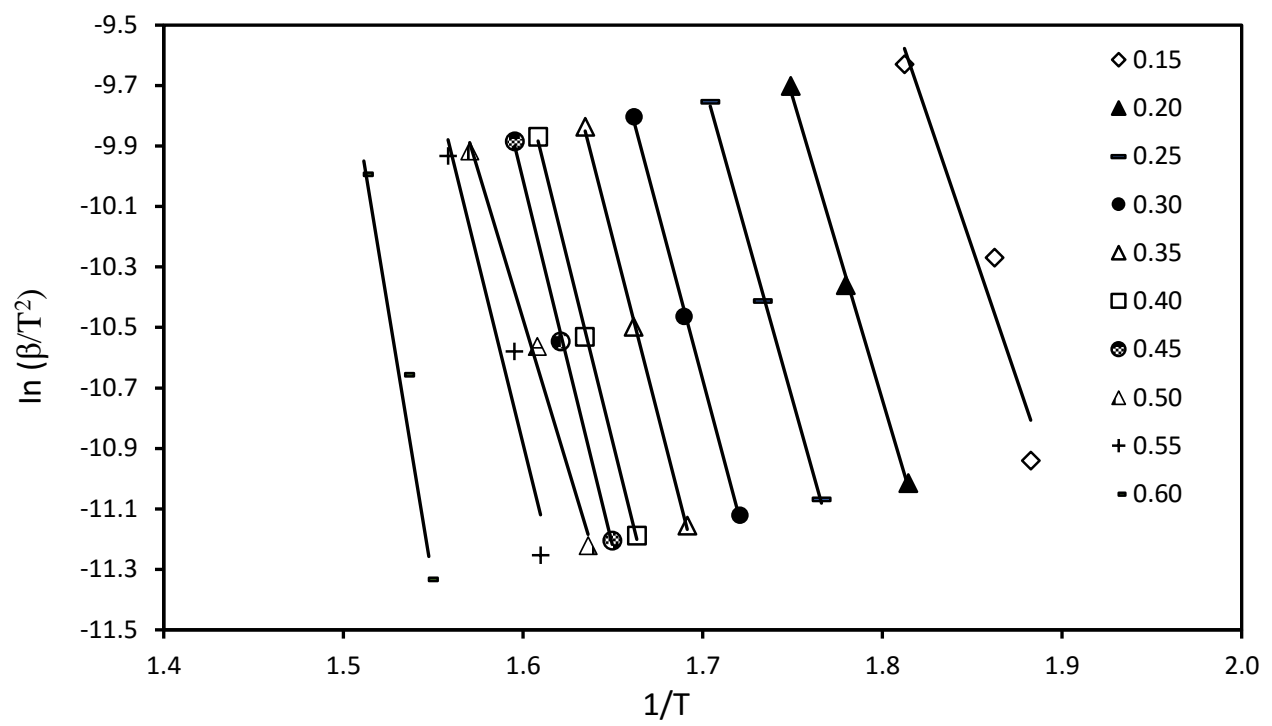

Fig. 4. Plots for determination of the kinetic parameters of MSH using DAEM.

The linear and parallel plots in Figure 4 indicate that for different $\mathrm{V} / \mathrm{V}_{\infty}$ from $0.15-0.6$ at various heating rates indicating MSH decomposition can be described by a set of first order reactions occurring simultaneously.

The kinetic parameters; $E$ and $A$ determined from Fig. 4 are presented in Table 3 for MSH decomposition from $\alpha=0.15-0.60$. The activation energy, $E$, clearly fluctuated from 145.44 to $300 \mathrm{~kJ} / \mathrm{mol}$ while frequency factor, $A$, ranged from $2.64 \times 10^{10}$ to $9.18 \times 10^{20} \mathrm{~min}^{-1}$. The average values for $E, A$ and $R^{2}$ are $193 \mathrm{~kJ} / \mathrm{mol}, 9.18 \times 10^{19} \mathrm{~min}^{-1}$ and 0.9832 , respectively. The fluctuating values of $E$ and $A$ highlight the complexity of the pyrolytic decomposition of MSH during thermal analysis.

TABLE 3. KINETIC PARAMETERS OF MSH USING DAEM MODEL

\begin{tabular}{cccc}
\hline Conversion $(\boldsymbol{\alpha})$ & Correlation $\left(\mathbf{R}^{\mathbf{2}}\right)$ & $\mathbf{E}(\mathbf{k J} / \mathbf{m o l})$ & $\mathbf{A}\left(\mathbf{m i n}^{-\mathbf{1}}\right)$ \\
\hline 0.15 & 0.9352 & 145.44 & $7.12 \times 10^{10}$ \\
0.20 & 0.9987 & 166.72 & $2.06 \times 10^{12}$ \\
0.25 & 0.9987 & 176.02 & $5.66 \times 10^{12}$ \\
0.30 & 0.9988 & 185.55 & $1.55 \times 10^{13}$ \\
0.35 & 0.9988 & 192.05 & $3.05 \times 10^{13}$ \\
0.40 & 0.9988 & 198.66 & $5.98 \times 10^{13}$ \\
0.45 & 0.9988 & 202.01 & $8.37 \times 10^{13}$ \\
0.50 & 0.9924 & 163.61 & $2.64 \times 10^{10}$ \\
0.55 & 0.9357 & 199.44 & $2.10 \times 10^{13}$ \\
0.60 & 0.9756 & 300.51 & $9.18 \times 10^{20}$ \\
\hline Average values & $\mathbf{0 . 9 8 3 2}$ & $\mathbf{1 9 3 . 0 0}$ & $\mathbf{9 . 1 8} \times \mathbf{1 0}^{\mathbf{1 3}}$ \\
\hline
\end{tabular}


The activation energy values increased from $145.44 \mathrm{~kJ} / \mathrm{mol}$ to $198.66 \mathrm{~kJ} / \mathrm{mol}$ at 0.15 to 0.40 , decreased at 0.5 before increasing to $300 \mathrm{~kJ} / \mathrm{mol}$ at 0.6 . This indicates that the conversion of MSH is slowest at conversion $\alpha=0.60$ towards the end of the thermal conversation process possibly due to the conversion of large molecular weight biomass components such as cellulose and lignin. In comparison the average $E$ value for $\mathrm{MSH}$ is lower than the reported values for corn stalk (203 kJ/mol), sawdust $(230 \mathrm{~kJ} / \mathrm{mol})$ and pine $(250 \mathrm{~kJ} / \mathrm{mol})$ reported in literature [20]. This indicates that the thermal decomposition of $\mathrm{MSH}$ is requires a lower minimum amount of energy for the reactants to thermally decompose into products compared to the other outlined agro wastes.

\section{CONClusion}

The study was aimed at investigating the thermochemical fuel properties of MSH. The results indicate that MSH is a cheap, abundant and potentially renewable solid biofuel for future clean energy and power generation. The thermochemical properties of $\mathrm{MSH}$ displayed high $\mathrm{C}, \mathrm{H}, \mathrm{O}$, $\mathrm{VM}$ and FC content which accounts for the high heating value (HHV) of $21.93 \mathrm{MJ} / \mathrm{kg}$. In addition, the Nitrogen $N$, and Sulphur $S$ content were less $1 \%$, indicating a low GHGs emission potential for MSH during thermal combustion. The ash content $A$, was less $5 \%$ indicating MSH may also possess a low probability for fouling and agglomeration if utilized as a SBF in boilers and gasifiers. Moisture content, $M$, was $7 \%$ which is within the acceptable limit $(<10 \%)$ required for thermal efficient operation of biomass conversion equipment. Overall the elemental and physicochemical properties of MSH were considerably lower compared to the values for other SBF reported in literature.

FTIR analysis revealed the MSH chemical structure may likely be due to contributions from a complex compounds namely: aliphatic, aromatic, ester, aldehydes, and ketone groups which form the major building blocks of hemicellulose, cellulose and lignin in solid biomass fuels. The influence of the complex chemical composition and effect heating rate on MSH decomposition was evident in the thermal behaviour of MSH. Although, the increase in heating rate resulted in an increased mass loss rate (MLR), it also resulted in an increase in char formation (residual mass) and shift in the TG/DTG curves of MSH due to the increased thermal resistance offered by evolving gaseous species during thermal decomposition.

The results for the thermochemical kinetics of MSH determined by DAEM (distributed activation energy model) showed that the parametric $E$ and $A$ values fluctuated during the thermal analysis which may be due to the complex nature of the pyrolytic decomposition of the components of MSH. However, the average values of $E=193.00 \mathrm{~kJ} / \mathrm{mol}, A=9.18 \times 10^{19} \mathrm{~min}^{-1}$ and $\mathrm{R}^{2}=0.9832$ were comparable to values for other biomass species reported in literature. In conclusion, the physicochemical and thermochemical properties of MSH determined in the study indicate it can potentially be deployed as quality feedstock with minimal technical challenges for thermal conversion in future biomass conversion equipment.

\section{ACKNOWLEDGMENT}

The contribution of Muhamad Faizal B. Abd Halim of PoCResT, Universiti Teknologi MARA is gratefully acknowledged. 


\section{REFERENCES}

[1] Sanderson K. Lignocellulose: A chewy problem. Nature 2011:474:S12-S14. doi:10.1038/474S012a

[2] Straathof A. J. Transformation of biomass into commodity chemicals using enzymes or cells. Chemical Reviews 2014:114(3):1871-908. doi:10.1021/cr400309c

[3] FAO, Melon Seed Statistics: Nigeria. FAOSTAT Statistics 2008-2013. 2015.

[4] Giwa S. O., Chuah L. A., Adam N. M. Fuel properties and rheological behavior of biodiesel from egusi (Colocynthis citrullus L.) seed kernel oil. Fuel Processing Technology 2014:122(0):42-48. doi:10.1016/j.fuproc.2014.01.014

[5] Elsheikh Y. A. Preparation of Citrullus colocynthis biodiesel via dual-step catalyzed process using functionalized imidazolium and pyrazolium ionic liquids for esterification step. Industrial Crops and Products 2013:49(0):822829. doi:10.1016/j.indcrop.2013.06.041

[6] Nehdi I. A. et al. Evaluation and characterisation of Citrullus colocynthis (L.) Schrad seed oil: Comparison with Helianthus annuus (sunflower) seed oil. Food Chemistry 2013:136(2):348-353. doi:10.1016/j.foodchem.2012.09.009

[7] Jarret R. L., Levy I. J. Oil and Fatty Acid Contents in Seed of Citrullus lanatus Schrad. Journal of Agricultural and Food Chemistry 2012:60(20):5199-5204. doi:10.1021/jf300046f

[8] Hussain A. I. et al. Citrullus colocynthis (L.) Schrad (bitter apple fruit): A review of its phytochemistry, pharmacology, traditional uses and nutritional potential. Journal of Ethnopharmacology 2014:155(1):54-66. doi:10.1016/j.jep.2014.06.011

[9] Mehta A. et al. Antimycobacterial activity of Citrullus colocynthis (L.) Schrad. against drug sensitive and drug resistant Mycobacterium tuberculosis and MOTT clinical isolates. Journal of Ethnopharmacology 2013:149(1):195-200. doi:10.1016/j.jep.2013.06.022

[10] Foo K., Hameed B. Preparation and characterization of activated carbon from melon (Citrullus vulgaris) seed hull by microwave-induced $\mathrm{NaOH}$ activation. Desalination and Water Treatment 2012:47(1-3):130-138 doi:10.1080/19443994.2012.696826

[11] Achigan-Dako E. G. et al. Importance and practices of Egusi crops (Citrullus lanatus (Thunb.) Matsum. \& Nakai, Cucumeropsis mannii Naudin and Lagenaria siceraria (Molina) Standl. cv.'Aklamkpa') in sociolinguistic areas in Benin. Biotechnology Agronomy, Society and Environment 2008:12(4):393-403.

[12] Ezeike G. O. I. Hygroscopic characteristics of unshelled egusi (melon) seeds. International Journal of Food Science and Technology 1988:23(5):511-519. doi:10.1111/j.1365-2621.1988.tb00608.x

[13] Vitali F. et al. Agricultural waste as household fuel: Techno-economic assessment of a new rice-husk cookstove for developing countries. Waste Management 2013:33(12):2762-2770. doi:10.1016/j.wasman.2013.08.026

[14] Kirsanovs V., Zandeckis A. Investigation of Biomass Gasification Process with Torrefaction Using Equilibrium Model. Energy Procedia 2015:72:329-336. doi:10.1016/j.egypro.2015.06.048

[15] Nyakuma B. B. et al. Gasification of Empty Fruit Bunch Briquettes in a Fixed Bed Tubular Reactor for Hydrogen Production. Applied Mechanics and Materials 2014:699:534-539. doi:10.4028/www.scientific.net/AMM.699.534

[16] Rusanova J. et al. Technological Alternatives or Use of Wood Fuel in Combined Heat and Power Production. Environmental and Climate Technologies 2013:12(1):10-14. doi:10.2478/rtuect-2013-0010

[17] Guerrero L. A., Maas G., Hogland W. Solid waste management challenges for cities in developing countries. Waste Management 2013:33(1):220-232. doi:10.1016/j.wasman.2012.09.008

[18] Barisa A. et al. Application of Low-Carbon Technologies for Cutting Household GHG Emissions. Energy Procedia 2015:72:230-237. doi:10.1016/i.egypro.2015.06.033

[19] Nyakuma B. B. et al. Non-Isothermal Kinetic Analysis of Oil Palm Empty Fruit Bunch Pellets by Thermogravimetric Analysis. Chemical Engineering Transactions 2015:45:1327-1332. doi:10.3303/CET1545222

[20] Li L. et al. Thermogravimetric and kinetic analysis of energy crop Jerusalem artichoke using the distributed activation energy model. Journal of Thermal Analysis and Calorimetry 2013:114(3):1183-1189. doi:10.1007/s10973-013-3115-2

[21] Ceylan S., Topcu Y. Pyrolysis kinetics of hazelnut husk using thermogravimetric analysis. Bioresource Technology 2014:156:182-8. doi:10.1016/j.biortech.2014.01.040

[22] Cheng G. et al. Kinetic Study on Pyrolysis of Blooming-forming Cyanobacteria. Energy Sources, Part A: Recovery, Utilization, and Environmental Effects 2015:37(6):625-632. doi:10.1080/15567036.2011.590866

[23] Nyakuma B. B. et al. Thermogravimetric Analysis of the Fuel Properties of Empty Fruit Bunch Briquettes. Jurnal Teknologi 2014:67(3). doi:10.11113/jt.v67.2768

[24] Shen D. K. et al. Thermal degradation mechanisms of wood under inert and oxidative environments using DAEM methods. Bioresource Technology 2011:102(2):2047-2052. doi:10.1016/j.biortech.2010.09.081

[25] Cai J., Liu R. New distributed activation energy model: numerical solution and application to pyrolysis kinetics of some types of biomass. Bioresource Technology 2008:99(8):2795-9. doi:10.1016/j.biortech.2007.06.033

[26] Sonobe T., Worasuwannarak N. Kinetic analyses of biomass pyrolysis using the distributed activation energy model. Fuel 2008:87(3):414-421. doi:10.1016/j.fuel.2007.05.004 
[27] Parikh J., Channiwala S., Ghosal G. A correlation for calculating HHV from proximate analysis of solid fuels. Fuel 2005:84(5):487-494. doi:10.1016/j.fuel.2004.10.010

[28] Miura K. A New and Simple Method to Estimate $\mathrm{f}(\mathrm{E})$ and k0(E) in the Distributed Activation Energy Model from Three Sets of Experimental Data. Energy \& Fuels 1995:9(2):302-307. doi:10.1021/ef00050a014

[29] Vladimir V. A theory of the irreversible electrical resistance changes of metallic films evaporated in vacuum. Proceedings of the Physical Society 1943:55(3):222. doi:10.1088/0959-5309/55/3/308

[30] Miura K., Maki T. A Simple Method for Estimating f(E) and k0(E) in the Distributed Activation Energy Model. Energy \& Fuels 1998:12(5):864-869. doi:10.1021/ef970212q

[31] Vassilev S. V. et al. An overview of the chemical composition of biomass. Fuel 2010:89(5):913-933 doi:10.1016/j.fuel.2009.10.022

[32] Natarajan E., Baskara Sethupathy S. Gasification of Groundnut Shells. Energy Sources, Part A: Recovery, Utilization, and Environmental Effects 2015:37(9):980-986. doi:10.1080/15567036.2011.601791

[33] Açıkalın K. Thermogravimetric analysis of walnut shell as pyrolysis feedstock. Journal of Thermal Analysis and Calorimetry 2011:105(1):145-150. doi:10.1007/s10973-010-1267-x

[34] Nyakuma B. B., Johari A., Ahmad A. Analysis of the pyrolytic fuel properties of empty fruit bunch briquettes. Journal of Applied Sciences 2012:12(24):2527-2533. doi:10.3923/jas.2012.2527.2533

[35] Nyakuma B. B. et al. Comparative analysis of the calorific fuel properties of Empty Fruit Bunch Fiber and Briquette. Energy Procedia 2014:52:466-473. doi:10.1016/j.egypro.2014.07.099

[36] Pattiya A. Thermochemical Characterization of Agricultural Wastes from Thai Cassava Plantations. Energy Sources, Part A: Recovery, Utilization, and Environmental Effects 2011:33(8):691-701. doi:10.1080/15567030903228922

[37] Lopez-Velazquez M. A. et al. Pyrolysis of orange waste: A thermo-kinetic study. Journal of Analytical and Applied Pyrolysis 2013:99:170-177. doi:10.1016/j.jaap.2012.09.016

[38] Yang H. et al. Characteristics of hemicellulose, cellulose and lignin pyrolysis. Fuel 2007:86(12-13):1781-1788. doi:10.1016/j.fuel.2006.12.013

[39] McKendry P. Energy production from biomass (part 1): overview of biomass. Bioresource Technology 2002:83(1): 37-46. doi:10.1016/S0960-8524(01)00118-3

[40] Islam M. A., Asif M., Hameed B. Pyrolysis kinetics of raw and hydrothermally carbonized Karanj (Pongamia pinnata) fruit hulls via thermogravimetric analysis. Bioresource Technology 2015:179:227-233 doi:10.1016/j.biortech.2014.11.115

[41] Damartzis T. et al. Thermal degradation studies and kinetic modeling of cardoon (Cynara cardunculus) pyrolysis using thermogravimetric analysis (TGA). Bioresource Technology 2011:102(10):6230-8 doi:10.1016/j.biortech.2011.02.060

[42] Slopiecka K., Bartocci P., Fantozzi F. Thermogravimetric analysis and kinetic study of poplar wood pyrolysis. Applied Energy 2012:97:491-497. doi:10.1016/j.apenergy.2011.12.056

[43] Idris S. S. et al. Investigation on thermochemical behaviour of low rank Malaysian coal, oil palm biomass and their blends during pyrolysis via thermogravimetric analysis (TGA). Bioresource Technology 2010:101(12):4584-4592. doi:10.1016/j.biortech.2010.01.059

[44] Chutia R. S., Kataki R., Bhaskar T. Thermogravimetric and decomposition kinetic studies of Mesua ferrea L. deoiled cake. Bioresource Technology 2013:139(0):66-72. doi:10.1016/j.biortech.2013.03.191

[45] Quan C., Li A., Gao N. Thermogravimetric analysis and kinetic study on large particles of printed circuit board wastes. Waste Management 2009:29(8):2353-2360. doi:10.1016/j.wasman.2009.03.020

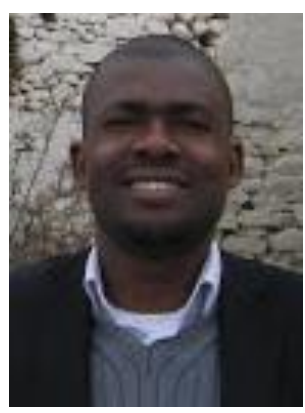

Bemgba Bevan Nyakuma is a trained chemist and energy engineer. He received his B. Tech degree (2006) in Industrial Chemistry with Merit Honours and an M. Sc, Ir. degree (2010) in Sustainable Energy Technology (SET) from Delft University of Technology (TU Delft), Netherlands. As part of his studies, B. B. Nyakuma has attended certified courses and training at various times at the Czech Technical University, (CTU) Czech Republic, Eindhoven University of Technology (TU Eindhoven), Netherlands and The Reactor Institute Delft (RID), Netherlands. He is currently a biomass researcher at the Institute of Future Energy, University of Technology Malaysia working on catalytic biomass gasification of oil palm waste for syngas production. His research interests include: biomass characterization, thermal biomass conversion technologies, reactor design, hydrogen production and storage, bio-energy policy, and coal conversion technologies. He has attended various international conferences and published in internationally recognised journals namely: Energy (Elsevier), Energy Procedia (Elsevier), Chemistry \& Chemical Technology (Ch\&ChT), Jurnal Teknologi (Scopus), Chemical Engineering Transactions, Applied Mechanics and Materials (Scopus). 